\title{
Acontecimento e problemas públicos: elementos para uma crítica da cobertura jornalística ${ }^{1}$
}

\section{Event and public issues: an outline for journalistic coverage criticism}

Terezinha Silva²

1 Uma primeira versão deste trabalho foi apresentada no I Simpósio de Crítica de Mídia: Como Criticam os que Criticam, realizado em 21 e 22 de setembro de 2017 na Universidade Federal de Santa Catarina (UFSC). 


\section{Resumo}

O artigo propõe pensar a crítica da cobertura jornalística de um acontecimento a partir de quatro dimensões: 1) enquadramento; 2) construção narrativa; 3) constituição do problema público ou questão coletiva; e 4) condicionantes do processo de produção. A partir dessa grade, é analisada a cobertura que as revistas Veja e Carta Capital realizaram da delação de executivos da Odebrecht, um dos acontecimentos da operação Lava Jato. O texto evidencia semelhanças e diferenças na forma como essas mídias interpretam o acontecimento e tratam o problema da corrupção, constroem uma narrativa e focam em certos atores e sua representação; além de apontar aspectos do processo produtivo que influem no tratamento dessas dimensões e na construção de diferentes coberturas jornalísticas, como as fontes de informação, a linha político-editorial e a relação de cada mídia com seu público.

Palavras-chave

Crítica da cobertura jornalística, acontecimento, problemas públicos, operação Lava Jato.

\section{Abstract}

The objective of this article is to analyze the criticism of journalistic coverage focused on an event considering four dimensions: 1) framework; 2) narrative construction; 3) creation of a public issue or collective question; 4) conditions of the production process. From this point of view, we analyzed the coverage made by two Brazilian magazines, Veja and CartaCapital, about the plea bargains from managers that work for the company Odebrecht. This was one of the events in Operation Car Wash. Our analysis shows resemblances and differences on how these magazines interpreted the event, handled the corruption problem, constructed a narrative and focused on some actors and their representations. We also present some characteristics of the production process that influence the treatment of these dimensions and the construction of different journalistic coverages, such as information sources, editor's political orientation and the relationship between each magazine and its own audience.

\section{Keywords}

Criticism of journalistic coverage, event, public issues, Operation Car Wash. 
O ponto de partida para a reflexão apresentada neste artigo é a relação que pode ser estabelecida entre acontecimentos e problemas públicos. Partimos do pressuposto de que a experiência pública é constituída e afetada por ocorrências que revelam problemas coletivos e que têm potencial de impulsionar debates e ações visando a sua resolução, um processo no qual o jornalismo e as mídias desempenham um papel central. Há certas ocorrências, como as relacionadas à operação Lava Jato, no Brasil, que têm essa dimensão de acontecimento público com alto potencial de revelação de questões coletivas que demandam discussão e ação públicas.

Inicialmente, apresentamos a concepção de "acontecimento" que orienta esta reflexão, inspirada na abordagem proposta por Quéré (1997; 2005) sobre a constituição social e simbólica de um acontecimento, na qual situamos o papel das mídias e da cobertura jornalística. Adaptamos as etapas do processo de "individualização do acontecimento" (QUÉRÉ, 2000; SILVA; SIMÕES, 2014; FRANÇA; LOPES, 2017) que consideramos pertinente para reconstituição, análise e crítica de uma cobertura jornalística, pois permitem observar os enquadramentos, a construção narrativa e o tratamento do problema público revelado pelo acontecimento. À grade com essas dimensões acrescentamos outra relativa ao processo de produção jornalística (apuração, destaque etc.), para explorar o modo como tal processo condiciona as três dimensões anteriores.

Por fim, exploramos esse modelo na análise da cobertura jornalística realizada por duas revistas de informação semanal (CartaCapital e Veja) sobre uma das ocorrências da operação Lava Jato: a delação de executivos da Odebrecht, que teve ampla repercussão público-midiática entre o final de 2016 e o primeiro semestre de 2017. Buscamos perceber como as duas revistas interpretam o acontecimento e elaboram sua construção narrativa e o problema público ali exposto, e como tal configuração se relaciona com as lógicas próprias do processo de produção de cada mídia jornalística. 


\section{A constituição do acontecimento e o papel do jornalismo}

Conceito importante nos estudos da comunicação e do jornalismo, o acontecimento tem sido abordado de distintas formas ${ }^{3}$. Dados os limites de espaço neste artigo, limitamo-nos a sintetizar aqui a abordagem proposta pelo sociólogo francês Louis Quéré $(1997 ; 2005)$, que temos adotado em nossas pesquisas. O autor inscreve o acontecimento no terreno da experiência e da ação, portanto, em sua recepção pública, ou seja, no modo como uma sociedade dele se apropria, buscando compreendê-lo, dando-Ihe sentido e respostas.

Quéré (2005) destaca a natureza dual do acontecimento (como fato no mundo e fonte de sentidos), enfatizando duas características marcantes. A primeira é o seu potencial hermenêutico, na acepção de que permite uma compreensão do mundo e de suas mudanças ao lançar luzes sobre o passado, presente e futuro e revelar processos em curso. A segunda é o seu poder de afetação, na medida em que um acontecimento sempre "acontece a alguém" (QUÉRÉ, 2005, p. 67): indivíduos ou coletivos que, afetados pelas questões reveladas pelo acontecimento, reagem às suas consequências, buscando reorganizar o fluxo normal da experiência. Para esse autor, uma ocorrência ou fato se constitui como acontecimento quando é capaz de interromper a normalidade da experiência cotidiana, provocar rupturas, revelar problemas públicos, abrir novas perspectivas de esclarecimento sobre o passado e possibilidades de futuro e desencadear novos sentidos e campos de ação, inclusive coletiva. Um acontecimento faz falar, agir e gera narrativas dentre elas, as jornalísticas (QUÉRÉ, 1997; 2005; FRANÇA, 2011; 2012; SILVA, 2014; SILVA; SIMÕES, 2014).

Consideramos que tal perspectiva permite atentar ao caráter coletivo do processo de constituição social e simbólica dos acontecimentos, problematizando e enriquecendo a compreensão de aspectos do trabalho de cobertura das ocorrências e construção narrativa efetuado pelos agentes jornalísticos. A esse respeito, a 
proposição de Quéré (2012) acerca da "dupla vida do acontecimento" contribui para pensar a relação entre as mídias jornalísticas e as ocorrências que elas cobrem e relatam. Segundo o autor, um acontecimento possui "duas vidas", isto é, provoca dois tipos de experiência interligadas. A primeira vida remete à dimensão existencial, sensível das ocorrências, ou seja, o acontecimento como mudança que interfere no cotidiano, o fato que deixa suas marcas empíricas e afeta indivíduos e coletividades. A segunda se refere ao acontecimento enquanto objeto da reflexão e do discurso, simbolizado pela linguagem, isto é, transformado em narrativa e comportando marcas do vivido (SILVA; FRANÇA, 2017).

Acreditamos que o jornalismo e a cobertura dos acontecimentos e temas atuam principalmente nessa segunda vida - na dimensão da simbolização, conforme destacado em outro trabalho:

O jornalismo constituiu uma "segunda vida" do acontecimento, construindo a sua narrativa. Não podemos negligenciar a primeira vida do acontecimento, sua existência sensível que afeta, que faz falar. Nem pensar na segunda vida como simples reflexo da materialidade que nos toca, minimizando os enquadramentos, os elementos de inteligibilidade acionados para interpretar os fatos do mundo que, por sua vez, são da ordem da cultura (SILVA; FRANÇA, 2017, p. 101).

A partir dessa perspectiva, entendemos que as coberturas jornalísticas desempenham um papel importante na constituição dos acontecimentos. A relevância de tal papel está associada mais diretamente a, pelo menos, três aspectos. Primeiro, porque os agentes jornalísticos selecionam e agendam ocorrências e temas, destinando-Ihes mais ou menos esforços de cobertura, espaço e tempo e, principalmente, promovendo enquadramentos conforme lógicas próprias de seus projetos editoriais, posicionamentos político-ideológicos e contratos comunicativos com seus públicos. Segundo, porque constroem narrativas nas quais destacam certas ações e atores, elaborando representações sobre eles, e acionam determinados passados e futuros para as ocorrências, restringindo ou ampliando as possibilidades de compreensão e sentidos para o acontecimento, as causas de sua emergência, as consequências para as quais ele aponta. Terceiro, 
porque, como destaca Quéré (2005), as mídias são suportes do debate público pelo qual as soluções para os problemas coletivos revelados pelo acontecimento são elaboradoras ou exploradas. Nessa configuração dos impasses ou questões problemáticas expostas pelos acontecimentos, as mídias e a cobertura jornalística têm um papel ambíguo, pois tanto dão visibilidade para demandas públicas, ações e propostas de tratamento de certos atores e perspectivas quanto dificultam o acesso ou relegam outros à invisibilidade. Além disso, a forma como uma questão coletiva é configurada no transcurso de um acontecimento é profundamente condicionada pela construção narrativa e pelos enquadramentos antes mencionados.

Tratam-se, pois, de conceitos importantes para pensar a análise e a crítica de coberturas jornalísticas. Enquadramento é compreendido aqui a partir da abordagem de Goffman (1991, p. 19) sobre os quadros da experiência: matrizes interpretativas ou de sentidos acionadas pelos atores para definir uma situação ou acontecimento e se posicionar naquela interação. Esses quadros de sentido "são construções socioculturais", que "os indivíduos mantêm, transformam, atualizam, em suas interações e relações sociais" (FRANÇA; SILVA; VAZ, 2014, p. 83).

Representação é entendida como universo simbólico, uma rede de significados que surgem na experiência dos indivíduos no mundo, uma construção que se realiza pela linguagem (HALL, 2016). Assim, os sentidos produzidos pelos discursos jornalísticos também constroem representações acerca dos atores a que se referem, as quais comportam elementos que compõem a imagem pública desses atores. Por fim, problemas públicos são compreendidos como aqueles impasses ou questões problemáticas que afetam públicos, no sentido de coletivos políticos que se constituem no contexto de um acontecimento (DEWEY, 1980; QUÉRÉ, 2005). Do jornalismo - e da cobertura que faz dos acontecimentos - tem-se a expectativa, constituída historicamente, de que atue nessa dimensão do interesse público relacionado a problemas coletivos, agendando-os e incorporando diferentes atores e perspectivas para seu debate público.

Assim, entendemos que a análise e a crítica da cobertura jornalística de um acontecimento - sobretudo daqueles que se mostram, desde sua emergência, 
com o poder de revelação e de afetação de que nos fala Quéré (2005) - podem ser enriquecidas se incluírem como dimensões: os enquadramentos; o modo como a construção narrativa configura a ação, a representação dos atores e a temporalidade do acontecimento; e o problema público ou questão pública evocada. São categorias que estão profundamente relacionadas, adaptadas das dimensões do processo de "individualização do acontecimento" (QUÉRÉ, 2005) com as quais temos trabalhado em outras pesquisas (FRANÇA, 2011; SILVA, 2014; SILVA; SIMÕES, 2014)4. Além dessas, entendemos que uma categoria de análise relativa ao processo de produção jornalística pode colaborar para observar certas características específicas da cobertura jornalística de acontecimentos e temas que condicionam os enquadramentos, a construção narrativa e o tratamento do problema público. Dentre os elementos-chave do processo de produção estão a apuração realizada, especialmente com as fontes informativas acionadas, e o destaque dado ao assunto - o que remete a duas importantes questões de fundo no processo de produção jornalística: a linha político-editorial de cada mídia e a relação com o público ${ }^{5}$.

Consideramos que as quatro dimensões são adequadas para a reconstituição e análise de coberturas jornalísticas de acontecimentos, sobretudo os que revelam questões coletivas. É o caso da delação da Odebrecht, que apresentamos na sequência a partir desse modelo composto por enquadramento, construção narrativa, tratamento do problema público e processo de produção jornalística.

Segundo Quéré (2000; 2005), a individualização ou individuação do acontecimento refere-se ao processo pelo qual uma ocorrência adquire sentido e identidade enquanto acontecimento único, singular. É constituído por fases ou dimensões interligadas: a descrição ou definição do acontecimento, para os quais são acionados quadros de sentidos (enquadramentos); a narração (constituição da temporalidade, identificação dos atores centrais e suas ações); a identificação do pano de fundo social e pragmático; a constituição do problema público; e a normalização do acontecimento (FRANÇA, 2011; SILVA, 2014; SILVA; SIMÕES, 2014). 


\section{A delação da Odebrecht na cobertura de Veja e CartaCapital}

A ocorrência que ficou conhecida como "delação da Odebrecht" refere-se a um conjunto de depoimentos que começaram a ser prestados por 77 executivos dessa empreiteira, a partir de dezembro de 2016, à força-tarefa da operação Lava Jato. Depoimentos centrais, como os de Marcelo e Emílio Odebrecht, ocorreram em diferentes momentos de março e abril de 2017. No entanto, o conteúdo de pré-delações de outros executivos começou a vazar à imprensa já em novembro de 2016 e, principalmente, no começo de dezembro daquele ano, quando das assinaturas dos acordos de delação entre o Ministério Público Federal e os executivos da Odebrecht. Desde seu início, a Lava Jato adotou como uma de suas principais estratégias - questionada por diferentes atores - o vazamento à imprensa de informações seletivas de investigações ainda em curso. Mídias como a revista Veja, por exemplo, têm desempenhado um papel importante na difusão das informações vazadas por agentes da operação.

A cobertura analisada aqui se refere ao período entre novembro de 2016 e abril de 2017, quando o ministro do Supremo Tribunal Federal, Edson Fachin, relator dos processos da Lava Jato, divulgou os pedidos de abertura de inquéritos contra os acusados nessas delações. Dado o tamanho do objeto, limitamos a análise a apenas algumas edições das revistas CartaCapital e Veja - duas publicações que representam linhas editoriais diferentes. O critério de seleção foi o destaque dado ao tema nas capas das revistas no período mencionado. Para a composição do corpus, selecionamos três edições da Veja nas quais a delação da Odebrecht foi destacada como manchete na capa (14 de dezembro de 2016, 8 de março de 2017 e 19 de abril de 2017). Da CartaCapital foram selecionadas três edições nas quais o assunto também foi capa - mas, nesse caso, o destaque foi apenas na forma de chamada (21 de dezembro de 2016, 22 de março de 2017 e 20 de abril de 2017). Analisamos cada uma das reportagens dessas edições a partir das dimensões antes mencionadas: a definição ou enquadramento do acontecimento "delação da Odebrecht", a construção narrativa, a constituição do problema público e os elementos do processo produtivo. É o que está exposto na sequência. 


\section{O enquadramento e a expectativa sobre o futuro dos atores}

$\mathrm{Na}$ descrição que fazem do acontecimento, os relatos das duas revistas destacam a singularidade da delação da Odebrecht em relação a similares realizadas no âmbito da operação Lato Jato. Sua singularidade está tanto no porte da empresa e sua longa história de vínculos com agentes políticos na contratação de obras públicas e financiamento de campanhas eleitorais quanto nas possíveis consequências dos conteúdos para dezenas de políticos de diferentes partidos. Trata-se, em ambas as revistas, da "delação da maior empreiteira do país" e do "maior acordo de delação premiada do mundo" (NATAL..., 2016, p. 25; A DELAÇÃO..., 2016).

A descrição das revistas recorre a metáforas ou comparações, principalmente com catástrofes naturais, para definir a situação e seus possíveis desdobramentos. CartaCapital define a delação como um "tsunami", convocando, para sua construção narrativa, o passado de relações permanentes entre a empreiteira e os poderes públicos e políticos no Brasil nas últimas décadas. Na cobertura da Veja, a "colaboração premiada" da Odebrecht com a Justiça é definida como "a delação do fim do mundo" - um "cataclismo", um "terremoto", "uma hecatombe", "uma bomba" cujos estilhaços atingem partidos, parlamentares e as maiores lideranças políticas do país (A DELAÇÃO..., 2016, p. 45).

É a partir dessa moldura de sentido - focada, sobretudo, no impacto do acontecimento sobre os atores políticos, sua imagem e nas expectativas em relação ao futuro deles e/ou de seus projetos - que as duas revistas enquadram inicialmente o acontecimento e constroem suas narrativas.

\section{A construção narrativa e a representação dos atores}

A semelhança entre CartaCapital e Veja, porém, não vai além da descrição inicial da delação como um "terremoto político" e de sua principal consequência - os prejuízos que pode provocar para os atores políticos e/ou seus projetos. A narrativa do acontecimento envereda por caminhos diferentes em cada uma das 
revistas, iluminando certos aspectos e deixando sombras sobre outros: atores e ações, passados e contextos.

Um dos aspectos mais importantes na análise das construções feitas pelas duas revistas é a ênfase que cada uma dá a determinados atores e não a outros, seja em termos de espaço dedicado ou da representação que deles fazem. Além disso, destaca-se a construção da temporalidade do acontecimento. Embora ambas priorizem as suas consequências para os diferentes atores, a CartaCapital rememora um passado distante de relações profundas entre a Odebrecht e os poderes públicos e políticos no Brasil, conforme visto na análise do enquadramento. Já a revista Veja convoca um passado bem mais recente a partir do qual narra a delação da Odebrecht, destacando o período dos governos do PT.

Em relação aos atores, a construção da CartaCapital enfatiza Michel Temer e seus aliados do eixo PMDB-PSDB ${ }^{6}$, como José Serra, Aécio Neves, Geraldo Alckmin, ministros e parlamentares peemedebistas. É o caso de Eliseu Padilha e Moreira Franco - qualificados como "prepostos" de Michel Temer para "negociar leis" de interesse da Odebrecht e arrecadar recursos da empreiteira. É o caso ainda dos senadores Renan Calheiros, Eunício Oliveira e Romero Jucá. Este último, posicionado no papel de principal "comerciante" de leis no Senado e "zeloso" defensor dos interesses da empresa.

A revista Veja também traz para sua narrativa todos esses atores (do PMDB e do PSDB) e com significativo espaço em seus textos e imagens. No entanto, é perceptível o quanto a revista é prudente na forma como representa Michel Temer. Defende, em alguns momentos, o papel de Temer como condutor das reformas que o Brasil precisa, diferentemente da CartaCapital.

Já esta última - embora mencione os executivos da Odebrecht, o expresidente Luiz Inácio Lula da Silva, a ex-presidenta Dilma Rousseff e outras lideranças do Partido dos Trabalhadores (PT) citadas nas denúncias desse período -, coloca ênfase sobre Michel Temer e seus aliados no governo. A noticiabilidade 
da delação da Odebrecht e de outras ocorrências da Lava Jato, mencionadas no corpus analisado, está ligada à possibilidade de associar as denúncias de corrupção a Temer e seus aliados. A narrativa construída pela Carta explora o pano de fundo dos interesses de Temer e seus aliados para: a) impedir investigações de denúncias de corrupção nas quais estão implicados, o que estaria na base do engajamento deles no afastamento de Dilma da presidência, e b) concretizar uma agenda política contra a qual a CartaCapital se posiciona explicitamente em seus textos.

Nessa revista, o acontecimento "delação da Odebrecht" é definido como um "terremoto político" pelo potencial que parece ter, naquele momento, de derrubar o governo Temer e uma agenda considerada como prejudicial à maioria da população. Dentro desse quadro, Michel Temer é representado pela CartaCapital como um governante cuja impopularidade e falta de legitimidade aumenta a cada nova delação. É um presidente engajado em acelerar seu "saco de maldades" (as reformas trabalhista e previdenciária, que a Carta considera "cruéis"), com o objetivo de "se segurar no cargo" (NATAL..., 2016, p. 24-25), mantendo o apoio do empresariado, do PSDB e da grande mídia, qualificada pela revista como "sócia do impeachment" de Dilma (ESCÁRNIO..., 2017).

Se o enquadramento da CartaCapital abre os sentidos da delação, contextualizando-a nas mudanças sociais e políticas em curso no país, o quadro delimitado pela Veja não permite ver além das próprias denúncias de corrupção e no seu potencial de atingir integrantes e aliados do PT, especialmente o expresidente Lula. O "terremoto" da delação na Veja também atinge vários atores e partidos; todos eles são mencionados no transcurso de sua cobertura com mais ou menos destaque. Mas, no eixo do bem contra o mal da construção narrativa dessa revista, estão, de um lado, a força-tarefa da Lava Jato - qualificada pelo discurso superlativo da Veja como "a maior e mais bem-sucedida investigação de corrução do mundo" (A REPÚBLICA..., 2017, p. 63) - e, de outro, a Odebrecht e os políticos, com destaque para o papel atribuído a Lula.

Na forma de representação dos atores, destaca-se na Veja a forma como a revista muda de posicionamento em relação à Odebrecht. Se no contexto das 
primeiras prisões de empreiteiros, em 2015, esses empresários eram as vítimas de achaques e extorsão de políticos vorazes, a Odebrecht figura agora na narrativa da Veja como "uma sucursal do crime" (A DELAÇÃO..., 2016, p. 44). A construtora passa a ser um "gigante da corrupção", com um "departamento de propinas" para distribuir "o dinheiro sujo [que] financiava a compra de leis, medidas provisórias e decisões que interessavam à empresa" (A DELAÇÃO..., 2016, p. 45; COMO..., 2016, p. 60; A REPÚBLICA..., 2017, p. 46-47).

No relato da revista, a operação Lava Jato teria interrompido esse "círculo mafioso" em junho de 2015, com a prisão de Marcelo Odebrecht (A REPÚBLICA..., 2017, p. 45). O "ex-príncipe" dos empreiteiros e seu pai, Emílio Odebrecht, ganham papel de destaque na narrativa da revista em função dos vínculos construídos com o PT e os governos petistas. Emílio teria promovido a aproximação com o PT quando Lula ainda era "aspirante ao Palácio do Planalto". "Tornou-se amigo de Lula", ajudando seu filho mais novo a se tornar um empresário e conseguindo, em contrapartida, a abertura ao governo Dilma. No passado que a Veja coloca como ponto de partida de sua narração - lançando sombras sobre um passado mais remoto -, a Odebrecht ampliou seus negócios com o poder público a partir do início do governo petista, período no qual a narrativa da revista diz que o "modelo de corrupção" do PT, do PMDB e do Partido Progressista (PP) na Petrobras "se reproduziu para praticamente todas as estatais" (A DELAÇÃO..., 2016, p. 45). Com um texto editorializado que caracteriza suas reportagens, uma matéria pós-abertura dos inquéritos contra 86 políticos acusados nas delações interpela o leitor a compartilhar do "espanto" que a Veja diz sentir em relação ao "poder paralelo" da Odebrecht no Brasil. O país "vivia sob uma cleptocracia", conforme o relato da revista, que enfatiza os dez anos anteriores à Lava Jato, ou seja, o passado recente, pós-governos do PT e aliados.

A ex-presidente Dilma e, principalmente, o ex-presidente Lula têm papel de destaque na narrativa sobre a "república da Odebrecht". Dilma é apontada como uma das responsáveis por sustentar o esquema de corrução que beneficiou a empreiteira ao longo dos governos petistas - "primeiro como ministra e, depois, 
como presidente" (A REPÚBLICA..., 2017, p. 57). Segundo a Veja, Dilma "sabia exatamente como funcionava o esquema de corrução na Petrobrás" e que o "dinheiro sujo" foi usado para financiar suas campanhas eleitorais (A REPÚBLICA, 2017, p. 57). A ênfase maior da revista, porém, é no ex-presidente Lula, representado como um ator que foi "capturado pela empreiteira", "um político pequeno", "um mandatário que se submetia ao papel de marionete nas mãos de empresários e, em contrapartida, se locupletava do poder com dinheiro oriundo de esquemas de corrupção"; uma figura que pode "vir a ostentar o título de presidente mais corrupto da história" e que estaria na iminência de ser preso: "Nunca antes na história deste país um presidente da República foi denunciado de modo tão arrasador" (A REPÚBLICA..., 2017, p. 55).

A construção narrativa das duas revistas, portanto, tem similaridade apenas no foco direcionado às práticas e representações de diferentes atores: Michel Temer e aliados, no caso da CartaCapital, Lula e/ou governos do PT e aliados, no caso da Veja. Na construção da temporalidade, porém, as diferenças são significativas. Ambas apontam para a possibilidade, em maior ou menor grau, de implicação dos atores citados em processos judiciais. Mas a CartaCapital aponta principalmente para a possibilidade de afastamento de Temer, inserindo-o no contexto das reformas que seu governo realiza no país e que seriam "cruéis" para a população. A Veja, por sua vez, aponta sobretudo para a iminência da prisão do ex-presidente Lula. No que se refere ao passado, a memória convocada pela revista lança luz especialmente sobre os governos do PT, aos quais associa mais diretamente a existência de uma "cleptocracia" e uma "república da Odebrecht". A CartaCapital busca em um passado mais longínquo às raízes para contextualizar e compreender o acontecimento presente e interpretar o problema das práticas de corrução entre agentes públicos e privados.

\section{O problema da corrupção: a ênfase nos atores e a criminalização da política}

A análise da cobertura da delação da Odebrecht mostra que Veja e CartaCapital configuram diferentemente o problema público evocado pelo acontecimento, que, 
de modo geral, denominamos corrupção. As questões expostas pelo acontecimento referem-se mais especificamente a, pelo menos, três práticas consideradas ilegais ou irregulares nas relações entre agentes públicos e privados, envolvendo o repasse de dinheiro para: 1) caixa dois de campanhas eleitorais de diferentes partidos; 2) propinas para destinação variada, como campanhas ou enriquecimento ilícito; e 3) comércio de leis no Congresso a partir do lobby de grandes empreiteiras.

O tratamento desses problemas na cobertura da Veja - conforme o material empírico analisado - sequer tangencia um esforço de esclarecimento ao leitor sobre o que é a doação eleitoral de campanha historicamente feita por empreiteiras e outras empresas no Brasil, as práticas de caixa dois e de propina. Embora a revista mencione de forma genérica um passado no qual o financiamento de campanhas políticas pela Odebrecht e repasse de propinas já era prática corrente, envolvendo "vários" políticos, partidos e ex-presidentes, a narrativa construída circunscreve o que chama de "poder paralelo" e "república da Odebrecht" principalmente à gestão do PT e seus aliados, com ênfase na figura do ex-presidente Lula.

As duas práticas irregulares antes mencionadas - caixa dois de campanha eleitoral e pagamento de propinas na relação entre políticos e empresários fazem parte de um "campo problemático" (Quéré, 2005), ou seja, um conjunto de problemas públicos conexos, há muito tempo existentes e persistentes no Brasil, comumente chamados de corrupção política. São problemas que se mantém ou retornam à cena pública à cada irrupção de um novo acontecimento, posto que não foram ainda devidamente discutidos e tratados pela ação pública.

Já a atividade de lobby e as diferentes formas de influência na criação de leis e normas no Congresso Nacional é, de fato, uma das novidades reveladas pelo acontecimento "delação da Odebrecht". Não que a prática seja nova; ao contrário, é comum há anos no Brasil e relativamente conhecida no meio político e jornalístico. Mas é a primeira vez que o comércio de leis e normas entre políticos e empresários é exposto a públicos mais amplos, por meio de um acontecimento 
de ampla repercussão7. Também nesse caso, de comercialização de leis e normas, o tratamento dado pela cobertura da Veja foca nos atores políticos acusados de receber propinas do empresariado, embora seja notável a mudança do tradicional enquadramento dos empreiteiros como vítimas de políticos corruptos. Na discussão dos problemas revelados, a revista limita-se a julgamentos e generalizações do tipo: "[a] enormidade do escândalo é uma evidência clamorosa de que a corrupção [...] é o que há de mais constante e de mais democrático na vida pública nacional" (A REPÚBLICA..., 2017, p. 47). A solução vislumbrada pela narrativa da Veja ao problema da corrupção vem do trabalho realizado pela Lava Jato e da penalização dos implicados. O relato incorpora apenas as interpretações e posicionamentos de operadores da Lava Jato, dentre as quais a prisão após condenação em segunda instância. A revista não apresenta outros atores e perspectivas para a discussão acerca das práticas de corrupção evocadas pela delação da Odebrecht.

CartaCapital, por sua vez, questiona e instaura um debate acerca da indistinção entre as formas de corrupção investigadas pela Lava Jato. Traz à discussão a iniciativa de Michel Temer, seus aliados na presidência da Câmara Rodrigo Maia -, do Senado - Eunício Oliveira - e do Tribunal Superior Eleitoral (TSE) - ministro Gilmar Mendes, do Supremo Tribunal Federal (STF) - de usar a sempre mencionada e ainda não implementada reforma político-eleitoral para anistiar o crime de caixa dois - "modelo reinante no país" há décadas, conforme a delação de Emílio Odebrecht, que a CartaCapital (ESCÁRNIO..., 2017, p. 21) relembra para contextualizar o histórico de um problema constante na atividade político-partidária. Traz também posicionamentos de diferentes atores questionando a distinção proposta por lideranças do PSDB - como Fernando Henrique Cardoso - , respaldadas pelo ministro Gilmar Mendes (TSE), entre um caixa "dois do bem" (financiamentos político-eleitorais) e "caixa do mal" (enriquecimento pessoal). A CartaCapital incorpora ainda ao debate do problema da corrupção no contexto

7 Uma das características de um escândalo é justamente o fato de publicizar, para públicos mais amplos, transgressões reais ou alegadas que já eram de conhecimento em círculos mais restritos (THOMPSON, 2002; ADUT, 2008), inclusive de jornalistas. 
daquele acontecimento a tese do Ministério Público de que uma doação eleitoral legalmente registrada pode ser considerada propina disfarçada. Essa é justamente uma das controvérsias acerca das ações e interpretações dos operadores da Lava Jato, questionadas por certos atores do meio político, jurídico e de mídias com o perfil editorial e posicionamentos político-ideológicos semelhantes aos da CartaCapital. Acionando fontes alternativas da própria Procuradoria da República, a revista aponta para o processo de "criminalização da política" que estaria em curso, em nome de sua suposta "depuração" (ESCÁRNIO..., 2017, p. 19).

As duas revistas, portanto, configuram de forma distinta o problema público (práticas de corrupção) evocado no contexto da delação da Odebrecht. Na Veja, trata-se de um problema comum na vida pública do país, embora sua narrativa circunscreva as práticas questionadas a certos tempos (recentes), coloque maior ênfase na responsabilização e penalização de alguns atores e em uma solução relacionada aos trabalhos da Lava Jato. Já a CartaCapital inscreve as práticas irregulares em um passado mais distante que contextualiza a permanência e dificuldade de tratamento do problema, assim como aponta para o possível risco de utilização e indistinção de práticas de corrupção para criminalização da política.

\section{Marcas da produção e influências na cobertura do acontecimento}

Para finalizar, destacamos alguns aspectos que consideramos os mais importantes no que se refere à observação de certas características percebidas no processo de produção jornalística da cobertura realizada pelas duas revistas, a partir das marcas percebidas nos textos analisados. Nessa dimensão, buscamos especialmente explorar possíveis influências do processo produtivo nas dimensões antes analisadas: enquadramento, construção narrativa e problema público. Enfatizamos as fontes de informação utilizadas e o destaque dado ao acontecimento, os quais estão relacionados à linha político-editorial de cada mídia jornalística e à relação estabelecida com seus públicos.

O destaque em quantidade de páginas, imagens, manchetes ou chamadas de capa e de números de edições é um indicador da relevância que cada uma dessas 
mídias concede ao acontecimento e do quanto atua para mantê-lo na agenda de discussão pública. Na cobertura analisada, a importância que a Veja atribui à "delação da Odebrecht" é perceptível pelo número de edições, capas e páginas destinadas a essa e outras ocorrências da Lava Jato. Nas três edições incluídas no corpus, as reportagens superam oito páginas, além de fotos e infográficos. Uma dessas reportagens ("A república da Odebrecht", de 19 de abril de 2017) ocupou 17 páginas da revista. Já na CartaCapital, com um total de três reportagens e média de seis páginas para cada, o assunto aparece de forma mais restrita, sempre diluído em meio a outros do contexto político-social do país - como as reformas trabalhistas e previdenciária e as manifestações de rua contra elas.

As fontes de informação acionadas na cobertura do acontecimento, por sua vez, são fundamentais, pois ajudam a compreender os laços existentes entre jornalistas e segmentos sociais no processo de enquadramento do acontecimento e dos problemas públicos, na sua contextualização e construção da temporalidade, na exploração de suas causas, na discussão de consequências e em propostas de tratamento. As reportagens da Veja são caracterizadas pela editorialização. Nos textos, praticamente não se identifica marcas de um processo de apuração e verificação jornalísticas; geralmente, sinalizam fontes de informação anônimas ligadas à Lava Jato ou remetem apenas a um "interlocutor ouvido" pela revista. Há também extenso uso de e referência a principais trechos de depoimentos aos quais a revista diz ter tido acesso. Além disso, é comum referenciar outros jornalistas. De modo geral, percebe-se a forte dependência da revista em relação aos vazamentos e às fontes da operação Lava Jato, sem um trabalho próprio de apuração jornalística, ilustrando bem o fenômeno do jornalismo sobre investigações (NASCIMENTO, 2010).

As interpretações dos agentes jornalísticos são, certamente, socioculturais: sentidos que circulam na sociedade e que são compartilhados intersubjetivamente por muitos. Importante, por isso, pensar a relação simbiótica, de interdependência, entre jornalistas e fontes de informação (NEVEAU, 2004). Diversidade de fontes de informação significa, potencialmente, diferentes possibilidades interpretativas 
de um acontecimento e dos problemas públicos tratados em uma cobertura. Além disso, as fontes não são atores de onde brotam naturalmente informações desinteressadas. No caso específico do acontecimento "delação da Odebrecht", os agentes da Polícia Federal e do Ministério Público presentes nas narrativas da Veja, geralmente de forma anônima, não são fontes neutras de onde provém somente ações e informações que interessam à coletividade; são corporações que também têm interesses específicos e disputam espaços de poder, para os quais é fundamental a ocupação da visibilidade nas mídias com suas interpretações acerca de acontecimentos, questões públicas e atores sociais. Assim, a seleção de fontes para abordar um acontecimento e os problemas que ele revela já sinaliza os quadros de sentido a serem mobilizados e as possibilidades de construção narrativa.

Para além das informações provenientes da Polícia Federal e do Ministério Público, a cobertura jornalística da Veja é feita basicamente a partir de um trabalho de curadoria jornalística: seleciona e reúne informações já difundidas por diferentes fontes, dando-Ihes sentidos que estão em consonância com sua linha editorial e seus posicionamentos político-ideológicos. A linha editorial de cada mídia é o lugar político a partir do qual elas falam, portanto, é um elemento importante a considerar na análise e crítica da cobertura jornalística. Trata-se de uma condicionante significativa do processo de produção (visível desde às fontes informativas priorizadas até o destaque dado ao assunto), dos enquadramentos, da construção narrativa (a temporalidade, os atores e suas ações e representações) e da configuração do problema público evocado pelo acontecimento, conforme a análise apresentada nos tópicos anteriores.

Assim como a Veja, a cobertura realizada pela CartaCapital trabalha com informações já divulgadas sobre o acontecimento e os problemas públicos; essa é, aliás, uma das características das revistas semanais de informação. No entanto, além dessas informações já conhecidas, de suas interpretações e posicionamentos explícitos, a CartaCapital traz diferentes fontes para suas reportagens. Também incorpora fragmentos de depoimentos das delações e fontes dos três poderes. 
Mas a principal diferença é que a revista apresenta vários atores da sociedade civil (cientistas políticos, sociólogos, cidadãos em manifestações de rua) como fontes de suas reportagens e interpretações. O que já aponta para outra forma de construção da narrativa, de interpretação do acontecimento e do problema público outro perfil de público e de relação com ele.

A relação que cada mídia busca construir e alimentar com seu público, portanto, é um importante aspecto a considerar em uma análise e crítica da cobertura jornalística - e merece ser melhor estudada e aprofundada pela pesquisa da área. Cada mídia dialoga com públicos específicos, grupos e indivíduos que compartilham valores, ideologias, interesses. As coberturas de Veja e CartaCapital se alimentam desse vínculo que procuram criar e/ou manter com os leitores. Se a Veja modificou o posicionamento em relação a uma empreiteira poderosa como a Odebrecht e a representação que fazia desses empresários, isso se deve, possivelmente, dentre outros fatores, à dificuldade de sustentar, ante o públicoleitor, a ideia de que os empreiteiros são meras vítimas da extorsão de políticos. O que nos coloca, também, a importância de observar a cobertura jornalística de um acontecimento ou tema em perspectiva histórica e em situações específicas.

Para concluir, retomamos a ideia da constituição social e simbólica dos acontecimentos (QUÉRÉ, 2005) como um processo resultante da ação e intervenção de outros atores e mediações, para além da instância midiática ou jornalística. Como destaca o autor, as mídias tomam emprestado de seu entorno sociocultural os procedimentos que utilizam para compreensão, atribuição de sentido e singularização dos acontecimentos.

As coberturas jornalísticas são práticas de comunicação nas quais se pode observar não apenas os processos de produção jornalística específicos de cada mídia na constituição de um acontecimento e de um problema coletivo como também as disputas de segmentos sociais - com os quais as mídias se relacionam ou representam - em torno do acontecimento e das questões coletivas que ele evidencia. 
Acreditamos que esses dois eixos podem ser observados a partir do modelo aqui esboçado para análise e crítica da cobertura jornalística por meio do enquadramento, da construção narrativa, da configuração do problema público e de aspectos específicos da produção do jornalismo. Tais dimensões permitem analisar as disputas de sentido travadas no processo de construção coletiva de um acontecimento e do tratamento dos problemas públicos, bem como o trabalho específico realizado por mídias jornalísticas na cobertura e interpretação das ocorrências, as implicações éticas envolvidas na configuração das questões coletivas e na representação dos atores, o modo como concebem o papel do jornalismo na sociedade e sua relação com os interesses da cidadania.

\section{Agradecimentos}

Agradeço ao Conselho Nacional de Desenvolvimento Científico e Tecnológico (CNPq) e à UFSC pelo apoio, por meio de uma bolsa de iniciação científica (IC) Edital Propesq/UFSC-01/2017 - , ao projeto de pesquisa com o qual este trabalho tem relação. Agradeço ao bolsista de IC, Eduardo Iarek, do Departamento de Jornalismo da UFSC, pela coleta do material empírico desta pesquisa.

\section{Referências}

A DELAÇÃo do fim do mundo. Veja, São Paulo, n. 2502, 2 nov. 2016.

ADUT, A. On scandal: moral disturbances in society, politics, and art. New York: Cambridge University Press, 2008.

A REPÚBLICA da Odebrecht. Veja: São Paulo, n. 2526, 19 abr. 2017.

BENETTI, M.; FONSECA, V. P. S. (Orgs.). Jornalismo e acontecimento: mapeamentos críticos. Florianópolis: Insular, 2010. v. 1. 
COMO a Odebrecht comprava o poder. Veja, São Paulo, n. 2508, 14 dez. 2016.

DEWEY, J. Os pensadores. São Paulo: Abril Cultural, 1980.

DEWEY, J. Le public et ses problèmes: extrait de "The public and its problems" (1927). Tradução Joelle Zask. Hermès, Paris, n. 31, p. 77-91, 2001.

ESCÁRNIO, até quanto? CartaCapital, São Paulo, n. 994, 22 mar. 2017.

FRANÇA, V. R. V. O crime e o trabalho de individuação do acontecimento no espaço midiático. Caleidoscópio, Lisboa, n. 10, p. 59-72, 2011. Disponível em: <https:// bit.ly/2qHbE6k>. Acesso em: 18 abr. 2018.

FRANÇA, V. R. V.; LOPES, S. Análise do acontecimento: possibilidades metodológicas. Matrizes, São Paulo, n. 3, v. 11, p. 71-87, set./dez. 2017. . O acontecimento para além do acontecimento: uma ferramenta heurística. In: FRANÇA, V. R.V.; OLIVEIRA, L. (Orgs.). Acontecimento: reverberações. Belo Horizonte: Autêntica, 2012. p. 39-51.

FRANÇA, V. V.; SILVA, T.; VAZ, G. F. F. Enquadramento (verbete). In: FRANÇA, V. R. V.; MARTINS, B. G.; MENDES, A. M. (Orgs.). Grupo de Pesquisa em Imagem e Sociabilidade (GRIS): trajetória, conceitos e pesquisa em comunicação. Belo Horizonte: Faculdade de Filosofia e Ciências Humanas; PPGCOM-UFMG, 2014. v. 1. p. 134-140.

GOFFMAN, E. Les cadres de l'experience. Paris: Les Éditions de Minuit, 1991.

HALL, S. Cultura e representação. Rio de Janeiro: Editora PUC-RJ; Apicuri, 2016. 
LEAL, B. S.; ANTUNES, E.; VAZ, P. B. (Orgs.). Jornalismo e acontecimento: percursos metodológicos. Florianópolis: Insular, 2011. v. 2.

MAROCCO, B.; BERGER, C.; HENN, R. (Orgs.). Jornalismo e acontecimento: diante da morte. Florianópolis: Insular, 2012. v. 3.

MOUILLAUD, M. Da forma ao sentido. In: MOUILLAUD, M.; DAYRELL, S. P. (Orgs.). O jornal: da forma ao sentido. 2. ed. Brasília, DF: Editora UnB. 2002. p. 29-35.

NASCIMENTO, S. Os novos escribas: o fenômeno do jornalismo sobre investigações no Brasil. Porto Alegre: Arquipélago Editorial, 2010.

NATAL de mau agouro. CartaCapital, São Paulo, n. 932, 21 dez. 2016.

NEVEAU, E. Sociologie du journalisme. 9. ed. Paris: La Découverte, 2004.

QUÉRÉ, L. Introduction. In: BEAUD, P. et al. (Eds.). Sociologie de la communication. [S. I.]: CNET, 1997. p. 415-432. (Coleção Réseaux : Communication, Technologie, Société, v. 1, n. 1).

. L'individualisation des événements dans le cadre de l'expérience publique.

In: BOURDON, P. (Org.). Processus du sens. Paris: L'Harmmatan, 2000. p. 1-23.

. Entre o facto e sentido: a dualidade do acontecimento. Trajectos: Revista de Comunicação, Cultura e Educação, Lisboa, n. 6. p. 59-75, 2005.

A dupla vida do acontecimento: por um realismo pragmatista. In: FRANÇA, V. R. V., OLIVEIRA, L. (Orgs.). Acontecimento: reverberações. Belo Horizonte: Autêntica, 2012. p. 21-38. 
SILVA, M. T. Acontecimento: evocando sentidos, provocando ações: uma análise do "Mensalão". Intexto, Porto Alegre, n. 30, p. 72-92, jul. 2014.

SILVA, G.; MAIA, F. D. O método análise de cobertura jornalística na compreensão do crack como acontecimento noticioso. In: LEAL, B. S.; ANTUNES, E. VAZ, P. B. (Orgs.). Jornalismo e acontecimento: percursos metodológicos. Florianópolis: Insular, 2011. v. 2. p. 37-54.

SILVA, T.; FRANÇA, V. Jornalismo, noticiabilidade e valores sociais. E-compós, Brasília, DF, v. 20, n. 3, set./dez. 2017. Disponível em: <https://bit.ly/2qJ0LS9>. Acesso em: 19 abr. 2018.

SILVA, T.; SIMÕES, P. G. Um acontecimento em disputa: sentidos da exumação de Jango. Estudos em Jornalismo e Mídia, Florianópolis, v. 11, n. 1, p. 34-50, 2014. Disponível em: <https://goo.gl/g98wYO>. Acesso em: 11 jan. 2016.

TEMER delata o golpe, e é delatado pela Odebrecht. CartaCapital: São Paulo, n. 949, 20 abr. 2017.

THOMPSON, J. O escândalo político: poder e visibilidade na era da mídia. Petrópolis: Vozes, 2002.

VOGEL, D.; MEDITSCH, E.; SILVA, G. (Orgs.). Jornalismo e acontecimento: tramas conceituais. Florianópolis: Insular, 2013. v. 4.

submetido em: 02 abr. 2018 | aprovado em: 29 abr. 2018 